\title{
The syntactic categories of adverbials in Isbukun Bunun [論郡社布農語狀語之句法範疇]
}

\author{
Hsiao-hung Iris $\mathrm{Wu}$ [吳曉虹] \\ National Taiwan Normal University [國立臺灣師範大學]
}

This paper examines the morpho-syntactic properties of elements that realize adverbial meanings in Isbukun Bunun and investigates how its adverbs are syntactically represented. I show that most adverbial meanings are realized as verbs in this language, with only a few adverbial expressions realized as adverbs in the traditional sense. Specifically, the adverbial verbs, just like typical verbs, have to occur sentence-initially, take inflectional morphology and attract cliticization, whereas the genuine adverbs are invariable in form and exhibit relatively free distribution. The paper also presents evidence which bears on the debate concerning the syntax of adverbials and shows that a hybrid treatment is needed in which phrasal adverbs are adjoined to clauses while adverbial verbs are located in strictlyordered functional projections in the backbone of the clause.

Keywords: adverbs, adverbial verbs, ordering, adjunction, functional projections, Isbukun Bunun

關鍵詞：副詞、副動詞、語序、加接、功能投影、郡社布農語

\section{Introduction}

This paper has two main objectives. Firstly, it gives a systematic description of adverbial modifiers in Isbukun Bunun (henceforth Isbukun). ${ }^{1}$ He et al. (1986) was

1. Bunun is subdivided into five dialects: Takituduh, Takbanuaz, Takibakha, Takivatan, and Isbukun. For a comparative study on Bunun dialects, readers can refer to P. Li (1988), where phonological and lexical differences among the five dialects are described. Previous works on Bunun adverbials (e.g., Su 2008, Holmer 2012) focused only on Takituduh Bunun, while no systematic investigation has been carried out on the Isbukun dialect. To fill this gap, I confine my 
the first work to give a descriptive overview of Isbukun adverbs and the defining feature of the so-called adverb category in their brief sketch of Isbukun grammar was mainly grounded on meaning and function. ${ }^{2}$ However, starting with Starosta's seminal work (1988), a number of studies have explored the phenomenon of adverbs or oft-called "adverbial verbs" in various Formosan languages (Hsiao 2004 for Atayal, Chang 2006 for Kavalan, Wu 2006 for Paiwan, Holmer 2006, 2012 for Seediq and Takituduh Bunun, C.-L. Li 2007 for Puyuma, Su 2008 for Takituduh Bunun, Chang 2009 for Tsou, P. Li 2016 for Thao, among others) and they have shown that adverbs (at least of certain types) are often morphologically and syntactically realized as verbal elements. Following this line of research, this paper attempts to examine the morpho-syntactic properties of elements that realize adverbial meanings in Isbukun and, accordingly, to arrive at a proper characterization of its adverb category. In particular, I will show that in Isbukun most adverbial meanings are realized as verbs, with only a few cases of adverbial expressions realized as a separate word class (adverbs) in the traditional sense, namely to be part of the extended projection of $\mathrm{V}$ in the sense of Grimshaw (1991). Note however that, for easier comparison, we occasionally use the term adverb when referring to the similar category in other languages or discussing the relevant syntactic theories. Secondly, this paper aims to understand how adverbials are syntactically represented in Isbukun. In particular, we look at the recent controversies regarding the syntactic licensing environments of adverbials. According to the "location-in-Spec" hypothesis (Cinque 1999, et seq.), adverbials are located in the specifier positions of distinct AdvPs and licensed via the general Spec-Head agreement relations. However, on the other hand, Ernst $(2002,2007)$ and Kaufman (2006) argue that adverbials should be analyzed as free adjunction to maximal projections and be constrained by appropriate semantic conditions. Recently, Holmer (2012) has further proposed a hybrid approach that incorporates the insights of the two aforementioned accounts: both specifiers and heads are possible positions for allocating adverbials, while the build-up of the clause structure hosting these adverbials is determined by semantic/scopal relations. Based on the available data that I gathered and the relative order I establish

attention to Isbukun Bunun in this work; particularly, the current study is based on the Isbukun dialect spoken in Taitung County. The informants I consulted were over 55 years old.

2. They distinguish seven sub-classes of adverbs, including time, location, degree, mood, interrogative, negation and manner adverbs. The focus of $\mathrm{He}$ et al. is mainly placed on the semantics and positioning while little attention is paid to the morpho-syntactic attributes of the adverbs themselves. Following the widely-discussed 'adverbial verb' view, the current work thus aims to approach this issue from a syntactic perspective and to further provide relevant formal grammatical discussion. 
for the main classes of adverbials in Isbukun, this paper also discusses the theoretically interesting implications on the pertinent adverbial licensing theories.

The paper is structured as follows. Section 2 presents the grammatical properties of adverbial modifiers in Isbukun. Section 3 investigates the ordering possibilities among different classes of adverbials and outlines the theoretical consequences that follow from the relevant data of Isbukun Bunun. Section 4 concludes the paper.

\section{Adverbial modifiers in Isbukun Bunun}

This section describes the morpho-syntactic properties of Isbukun adverbials. Below, each category is introduced and grouped based on the classifications discussed in Cinque (1999) and Ernst (2002), accompanied by at least one English adverb example in parentheses as illustration.

(1) Semantic classes of adverbials

i. Mood
a. speech-act (e.g., frankly)
b. evaluative (e.g., fortunately)

ii. Modal
a. epistemic (e.g., seemingly)
b. deontic (e.g., necessarily)
c. volitional (e.g., intentionally)

iii. Aspect
a. habitual (e.g., usually)
b. repetitive/additive (e.g., again)
c. frequentative (e.g., sometimes)
d. prospective (e.g., almost)
e. completive (e.g., completely)

iv. Voice

manner (e.g., quickly, secretly)

v. Emphatic (e.g., really, also)

vi. Locational/temporal (e.g., at home, today)

Drawing on the results of three major diagnostics - word order, inflectional morphology and clitic placement - the following shows that the so-called adverbial modifiers in Isbukun bear typical verbal properties and behave as verbs, except for the spatiotemporal modifiers and the emphatic adverbials amin 'also' and tutupa 'really'. 


\subsection{Order placement}

Isbukun is a predicate-initial language in terms of default/neutral word order; ${ }^{3}$ elements that serve as the main predicate in a given sentence must appear in the sentence-initial position.

(2) Ma-ludah a Tahai mas Aping. ${ }^{5}$

$\mathrm{AV}^{4}$-beat NOM Tahai ACC Aping

'Tahai beats Aping.'

Just like common lexical verbs, most adverbial modifiers must occur in the sentence-initial position and precede the verbs they modify. (3) provides examples of manner adverbial modifiers. ${ }^{6}$

(3) a. Ma $<$ i $>$ biskav sa'ia m-udadaan. ${ }^{7}$

(manner)

$\mathrm{AV}<\mathrm{PFV}>$ quickly 3sG.NOM AV-walk

'He walked quickly'.

b. Ma-kamingmiing Tahai ma-labut sanglav.

AV-secretly Tahai AV-uproot vegetable

'Tahai uprooted the vegetable secretly'.

c. Ma-nanulu a Dahu ansahan mas danum.

AV-carefully Nom Dahu AV.carry ACC water

'Dahu carefully carries the water.'

3. When a special or marked information structure is at stake, it is possible to use the marker hai to front a non-verbal element and introduce it as the topic of the sentence, as shown below (cf. Jeng 1977).

(i) Dahu hai miliskin tu ma-baliv lumah-cia.

Dahu TOP AV.plan LNK AV-buy house-that.OBL

'Dahu plans to buy that house.'

4. The abbreviations used in this paper are available in the list of abbreviations.

5. The orthographic notation follows the system announced by the Council of Indigenous People and Ministry of Education in 2005. The morphological boundaries are indicated by hyphens. Infixes are enclosed by angle brackets.

6. We start the discussion by introducing the manner adverbial modifiers since they are widely observed to be realized as verbs in many, if not all, Formosan languages. Then we proceed in a bottom-up fashion to introduce the hierarchically lower adverbials (i.e., aspect-related) to higher ones based on Cinque's model. Later, special cases which are in stark contrast to most adverbial expressions are discussed.

7. One relevant issue is about the status of adjectives in Isbukun. It has been observed that there is no distinct adjective class in a number of Formosan languages (Yeh 2003, Ross \& Teng 2003, Wu 2004, Zeitoun 2007). In Isbukun, adjectives apparently behave as (intransitive) verbs as well though their status needs further scrutiny. Note that, even if we assume along with $\mathrm{He}$ 
Note that the ordering is rigidly observed and not transportable; if the word order is switched, ungrammaticality arises.

(4) *M-udadaan sa’ia $\quad$ ma<i $>$ biskav.

AV-walk 3sG.NOM AV $<$ PFV $>$ quickly

Similar clause-initial requirements are observed with Aspect-related, Modal and Mood adverbial modifiers as demonstrated in order from (5)-(7).

(5) Aspect-related adverbials

a. Ma-zingzav-in sa’ia kanahtung is-kuzakuza.

(completive) AV-completely-PRF 3sG.NOM Av.finish NML-work 'He completely finished the work.'

b. Mungaa-in sa'ia munhanu. (prospective) AV.almost-PRF 3sG.NOM AV.float 'He almost floated away'.

c. $\quad \mathrm{M}<$ in $>$ us'an Tahai ma-ludah zaku. ${ }^{8}$ (frequentative) $\mathrm{AV}<\mathrm{PFV}>$ once Tahai AV-hit 1sG.ACC 'Tahai hit me once.'

d. Mu-uhna sa'ia huud davus, aat misbusuk-in. AV-again 3sG.NOM AV.drink wine and AV.drunk-PRF 'He drank again and (so) got drunk.'

e. Alusbut-an-ku a babu-a mapa-kaun. (habitual) usually-LV-1SG.OBL ${ }^{9}$ NOM pig-DEM.NOM AV.cause-eat 'The pigs are usually fed by me.'

(6) Modal-related adverbials

a. Kamananu sa'ia savaivai zaku. (volitional) AV.intentionally 3sG.NOM Av.bully 1sG.ACC 'He intentionally bullied me.'

b. Asa kata tu sahusbu 'anak'anak tu halinga. AV.must 1PL.NOM LNK AV.value self LNK language (repetitive) 'We must value our own language.'

et al. (1986) that Isbukun has a separate adjective category and that they, unlike verbs, cannot take morphological forms denoting the past, our point still holds. Explicitly, in (3a) the modifier mabiskav takes the past-denoting affix -in-and thus, according to $\mathrm{He}$ et al., it shouldn't be viewed as an adjective in this case.

8. The form mazaku is often commonly used for the 'object' function in the dialect spoken in Taitung.

9. Readers can refer to L. Li $(2010,2017,2018)$ for a detailed discussion of oblique clitic pronouns in Isbukun. 
c. M-aszang Tahai ma-dahpa, aupa ma-mas'i. (epistemic) AV-seemingly Tahai AV-sick because AV-cough 'Seemingly, Tahai is sick since he keeps coughing.'

(7) Mood-related adverbials ${ }^{10}$

a. $\mathrm{Ma}<\mathrm{i}>$ taisah, ma-aipi isaicia tama min-dadu. (evaluative) $\mathrm{AV}<\mathrm{PFV}>$ luckily AV-soon 3sG.GEN father AV-recover 'Luckily, his father soon recovered.'

b. Tumantuk, ma-nau'az a Abus-an. (speech-act) AV.tell-the-truth AV-pretty NOM Abus-DEM.NOM 'To tell the truth, Abus is pretty'

The adverbial modifiers illustrated above are required to occur sentence-initially, which is in conformity with common verbs. However, the fixed initiality requirement does not apply to all adverbial modifiers. As illustrated in (8), temporal and locational expressions enjoy much freer distribution and can occur in a sentence medial or final position.
a. $\mathrm{Na}$ ku-isa
kasu
aip?
FUT AV.to-where 2sG.NOM today
'Where are you going today?'
b. Na m-udaan kata saincin ku-sia pasnanavaan.
FUT AV-walk 2PL.NOM here to-P school
'We'll depart from here to school'.

Moreover, the emphatic adverbs amin 'also' and tutupa 'surely' can manifest themselves in other clausal-internal positions than clause-initially, as illustrated in (9).

(9) a. Abus hai $s<$ in $>$ adu mas isaicia tu cina, maupacia amin Aping. Abus TOP AV $<$ PFV $>$ see ACC 3sG.GEN LNK mother AV.so also Aping 'Abus saw her mother, and so did Aping.'

b. Min-sial tutupa isaicia lutbu.

Av.become-good surely 3sG.Gen body

'His body will surely get better.'

These property evidently distinguish themselves apart from the other aforementioned adverbials, which are shown to necessarily take a sentence initial position. In this respect, we can thus conclude that, except for amin 'also', tutupa 'surely' and

10. For adverbials of evaluative and speech-act types, a pause (signaled by a comma in the transcription here) usually follows. This property is similar to English and is well-expected since these adverbials are considered to express a speaker's positive, negative, or other attitude towards the state of affairs described in a proposition, thus modifying and scoping over the entire following clause. 
temporal/locational adverbs, the adverbial modifiers in Isbukun behave on a par with run-of-the-mill verbs in their word order possibilities.

\subsection{Inflectional morphology ${ }^{11}$}

As is well-known, in many other Formosan and Western Austronesian languages, verbs must bear their associated morphology marker; that is, the semantic role or grammatical function of the surface subject has to be encoded in the verb. Just as most Austronesian languages that display a four-way distinction in their voice systems, Isbukun distinguishes four different voice constructions: actor voice (AV, realized as $m a-, m-, \varnothing)$, patient voice ( $\mathrm{PV}$, realized as - $u n)$, locative voice (LV, realized as - $a n$ ) and beneficiary voice ( $\mathrm{BV}$ realized as is-). The subject of a clause, usually marked by the nominative case marker $a$, can thus be identified by the voice marking on the verb. ${ }^{12}$

Furthermore, Isbukun verbs are able to carry morphological markers to indicate tense/aspect and mood, though the status of some markers remains controversial in the literature and should be treated with caution. For instance, PRF -in is often seen to immediately follow a verb. Due to this distribution, He et al. (1986), Huang (1997), P. Li (1997) and Zeitoun (2000) consider -in a suffix attached to the verb. By contrast, Lin (1996) and L. Li (2010) propose that PRF -in should be viewed as a clitic, following an initial element regardless of its syntactic category. Similar disagreement exists concerning the status of the future marker na. In the literature, FUT $n a$ is often treated as a verbal prefix; however, Nojima (1996) and Jeng (1999) consider $n a$ to be a free-standing form whereas Lin (1996) and L. Li (2010) propose that it should be seen as a clitic since it does not necessarily attach to a verb. Owing to these considerations, in the following morpho-syntactic tests which are used to demonstrate the inflection-bearing ability of verbs, we will only employ the relatively uncontroversial verbal affixes, namely the voice markers, PFV infix $<$ in $>$ and imperative markers.

The same as regular verbs, most adverbial modifiers in Isbukun need to carry corresponding voice morphological affixes. This can be seen in the earlier Exam-

11. Here I assume inflectional morphology marks relations such as voice, tense, aspect, mood and thus it essentially creates new forms of the same word in a relevant sense, with the core lexical meaning staying alike (cf. Stump 2001).

12. The algorithm of Isbukun clause-level verbal case assignment goes as follows: if a nominal expression has the grammatical function of subject, it is preceded by and marked with the nominative case $a$; otherwise, it is marked with the non-subject marker mas (P. Li 1997, Huang et al. 1999, H. Huang 2008, Shi 2009). It is essential to bear in mind that the dichotomous formal case marking system adopted in this paper cannot be taken to mean a two-way distinction in function since the case marker for non-subject NPs may mark arguments or obliques. 
ples (3) \& (5)-(7), where it is clear that voice marking is necessarily registered on the adverbial verb. Moreover, as observed in Chang (2009), in many Formosan languages the adverbial verbs entertain certain voice alternations though these are mostly restricted to two (i.e., AV and PV); a similar tendency is attested in Isbukun. ${ }^{13}$ It is possible for the adverbial verbs to be inflected with non-AV voices. (10) gives some illustrating examples. ${ }^{14}$

(10) a. Kananulu-un sa'ia m-alsivit aupa na tanghaiiu.

carefully-PV 3sG.NOM AV-watch because FUT AV.steal

'He is carefully watched for he tends to steal things.'

b. Pizingzav-un isaicia is-kuzakuza ${ }^{15}$ kuzakuza. completely-PV 3sG.GEN NML-work AV.work

'His work was completely done.'

c. Asa-un-ku maza huma is-baliv.

must-PV-1sG.OBL those farm BV-buy

Lit.: 'Those farms are necessarily bought by me.'

'I must buy those farms.'

In addition, the adverbial verbs are able to bear tense/aspect and imperative/optative mood morphology, which is, again, suggestive of their verbal nature. The former fact (i.e., the possibility of taking tense/aspect morphology) has been shown in earlier examples, in particular (3a), (5c) and (7a): aspectual inflections usually fall on verbs, but the aspectual affixation will necessarily shift to the preceding adverbial verb if there is one. Furthermore, the following examples demonstrate that adverbial verbs can serve as the verbal basis of imperative or optative morphology under appropriate conditions.

(11) a. Ma-nanulu-a mudadaan ii, na kanbuszih mas utan.

AV-carefully-IMP AV.walk PART FUT AV.step ACC yam

'Walk carefully; otherwise you'll step on the yams.'

b. Mu-uhna-ang ma-saiv-ku tasa tu bunbun. ${ }^{16}$

AV-again-OPT AV-give-1sG.OBL one LNK banana

'Give me a banana again please.'

13. This is not a rigid restriction though; for instance, alusbut 'usually' in (5e) can take the LV voice.

14. To keep the discussion within manageable proportions, in Section 2.2 \& 2.3 I give one illustrating example from each major type of adverbials.

15. The morpheme is- is a nominalizer that creates nouns from action verbs (cf. L. Li 2018). In addition to is-kuzakuza 'work' in (10b), two more examples are provided below.

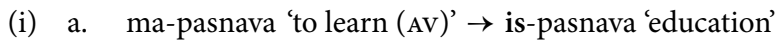

b. m-ihumis 'to live (Av)' $\rightarrow$ is-'ihumis 'life'

16. The -ang morpheme here is used to express a wish or a hope. It can also be used to deliver a polite request in some cases, thus marked as expressing optative mood here. 
In stark contrast, the temporal/locational modifiers, aip 'today' and takna 'yesterday', and emphatic adverbs amin 'also' and tutupa 'surely', which were earlier shown to display flexible placement in a clause, cannot host any voice, tense/ aspect or imperative affixes; rather, it is always their modified verbs that inflect, as illustrated in (12)-(14). Accordingly, in this respect they behave as typical adverbs in that they lack the ability to bear inflectional morphology of any kind.

(12) a. Sinav-un-ku aip sinkakaun.

wash-PV-1SG.OBL today pot

'Today the pot was washed by me'

b. A<i>taz-an sa'ia mas maluspingaz takna.

die $<$ PFV $>$ LV 3sG.NOM OBL wife yesterday

'His wife died on him yesterday.'

c. Ulav- $a v$ a bainu aip.

pick-IMP NOM peanut today

'Pick the peanuts today!'

(13) a. Bizakbizak-un amin a lukis, aat mulampas-in.

shake-PV also nOM tree then AV.uproot-PRF

'The tree was also shaken violently and then uprooted.'

b. $S<$ in $>$ adu amin Aping mas ivut-cia.

$\mathrm{AV}<\mathrm{PFV}>$ see also Aping ACC snake-DEM.ACC

'Aping also saw that snake.'

c. Baliv- $a v$ amin a sanglav-a.

buy-IMP also NOM vegetable-DEM.NOM

'Also buy some vegetables!'

(14) a. Hanup tu bunun mais sadu cici hai, pataz-un tutupa.

AV.hunt LNK person when AV.see prey TOP kill-PV surely

'When a hunter sees his prey, it will surely be killed.'

b. $M<$ in $>$ aun-in sa'ia mas utan-cia tutupa.

AV $<$ PFV $>$ eat-PRF 3sG.NOM ACC yam-DEM.ACC surely

'He surely ate those yams.'

c. Ma-pacis'u- $a$ huud davus tutupa.

AV-quit-IMP AV.drink wine surely

'(You should) definitely quit drinking!'

\subsection{Clitic attachment}

In Isbukun, clitics are able to cliticize onto lexical verbal heads given an appropriate syntactic environment, as shown in (15) (see L. Li 2010 for a more detailed discussion on Isbukun cliticization). 
(15) Ludah-un-ku-as mais muliva kasu.

hit-PV-1SG.OBL-2sG.NOM when AV.err 2sG.NOM

'You will be hit by me when you make a mistake.'

As illustrated in (15), the lexical verb ludahun 'hit' can take the first-person singular oblique clitic pronoun $k u$ as well as the second-person nominative clitic as to be its arguments. Similar to plain lexical verbs, adverbial modifiers allow clitic pronouns to be attached to them: in (16) the adverbial modifiers makamingmiing 'secretly' and alusbutan 'usually' respectively take a clitic pronoun as their verbal dependent, which clearly shows that they behave like common lexical verbs syntactically.

(16) a. Ma-kamingmiing-ik tanghaiiu kakaunun.

AV-secretly-1sG.NOM AV.steal food

'I stole the food secretly'.

b. Alusbut-an-ku a babu-a mapa-kaun.

usually-LV-1sG.OBL Nom pig-DEM.NOM AV.cause-eat

'The pigs are usually fed by me.'

Nevertheless, the spatiotemporal and focus-sensitive adverbs amin 'also' and tutupa 'surely' are never permissible hosts for accommodating clitics to be attached to them, as shown in (17).
a. Na haipu-un-ku vai-an aip.
FUT attend-PV-1sG.OBL toddler-DEM.NOM today
'This toddler will be attended to by me today.'
b. ${ }^{*} \mathrm{Na}$ aip-ku haipu-un vai-an. ${ }^{17}$
c. Na ku-diip-ik amin.
FUT AV.to-that.place-1sG.NOM also
'I will go too.'
d. ${ }^{\star} \mathrm{Na}$ amin-ik ku-diip.
e. Ma-daidaz-ta uvaaz tutupa.
AV-love-1PL.NOM child surely
'We surely love children.'
f. ${ }^{\star}$ Tutupa-ta ma-daidaz uvaaz.

To summarize, in this section we have examined adverbial modifiers in Isbukun based on emblematic predicate-like properties, including ordering placement, verbal morphology and clitic attraction. We have shown that, syntactically, aside

17. Since clitics never attach to postverbal elements, aip in (17b), amin in (17d) and tutupa in (17f) are placed in sentence-initial positions so as to exclude the possible placement interference and to really demonstrate their inability in hosting clitics. I thank the reviewers for this suggestion. 
from the emphatic adverbs amin 'also' and tutupa 'surely' as well as spatiotemporal adverbs, the majority of Isbukun adverbials behave alike to run-of-mill predicates in that they meet the verb-initiality requirement, take morphological inflection which are usually encoded in verbs, and serve as possible hosts for cliticization. ${ }^{18}$ Taken altogether, Isbukun adverbials are not a homogenous group and at least two types must be distinguished: while most types of adverbial meaning are realized by elements which are morphosyntactically identified as verbal heads, some adverbials are better understood as adverbs in the traditional sense, namely nonhead maximal projections. Before we proceed, note on the other hand that, just as widely-attested in a variety of languages, temporal and locational expressions in Isbukun can also be argued to be nominal; ${ }^{19}$ for instance, like common noun phrases, they are able to be topicalized as in (18) and can occur as objects of prepositional elements like in (19), which further differentiates themselves from the emphatic adverbs amin and tutupa. ${ }^{20}$
a. Ludun-a
hai, mastan ma-saunghu.
mountain-DEM.NOM TOP AV.more AV-steep
'That mountain is steeper.'
b. Takna hai, ma<i>tapul saikin mas lapat. yesterday TOP AV $<$ PFV $>$ pick 1sG.NOM OBL guava 'Yesterday, I picked guavas.'
c. Saincin hai, madia batu.
here TOP AV-many stone
'Here, there are many stones.'

18. As pointed out by one reviewer, there are numerous examples in other Formosan languages, including other variants of Bunun, where the adverbial verbs do not necessarily possess all of the head-like properties (cf. Holmer 2006). In other words, it is possible for some elements to occur in preverbal head-like positions and attract clitic pronouns without being able to bear verbal inflection. Isbukun Bunun is no exception in this respect. For instance, the adverbials mus'an 'once' (5c) and maszang 'seemingly' (6c) do not bear any other voice inflection than AV but they can serve as hosts for cliticization and appear sentence-initially. I thank the reviewer for urging me to clarify this point.

19. In the present discussion, the temporal and locational expressions refer to terms without any adpositions, introducing them such as takna 'yesterday' and saincin 'here'. Since our purpose is to investigate the syntactic category of apparent adverbs and also since the categorial status of expressions with prepositions (e.g., sia ludun 'on the mountain') is uncontroversial, we only focus on the simple spatiotemporal terms here.

20. Note though both nominal and verbal spatiotemporal expressions are attested in some Formosan languages (e.g., Thao in P. Li 2016). 
(19) a. Ka-lumah sa'ia sia ludun-cia.

Av.build-house 3sG.NOM P mountain-DEM.OBL

'He built a house on that mountain.'

b. Dahu hai, paisna ${ }^{21}$ takna masapah sau-laupaku.

Dahu Top from yesterday Av.sleep until-now

'Dahu slept from yesterday until now.'

c. naia hai, paisna-diip ma-baliv bunglai.

3PL.NOM TOP from-that.place AV-buy pineapple

'They buy pineapples from there.'

Therefore, in the following theoretical discussion, we will not deal any further with expressions of time/place given that nominal elements are known to demand a very different licensing syntax than adverbials.

\section{Adverbial ordering and its implications on the syntax of adverbials}

In the recent syntax literature, the ordering variation among adverbials has received a great deal of attention and led to intense debate. The debate mostly centers around the problem of whether a universal ordered sequence of adverbials, and accordingly a universal hierarchy of functional projections, exists and, if yes, such a fixed hierarchy is primitive or determined by higher order (e.g., semantic) conditions. Also, the debate raises issues on the exact syntactic relations between those adverbials and the adverb-related functional projections. As a result, different hypotheses can be distinguished in regard to the syntactic position of adverbials and the factors which determine adverbial ordering in a given language. Following this line, this section approaches the relevant issues by examining the adverbial ordering patterns in Isbukun, based on which I further discuss the consequent theoretical implications.

\subsection{Data and generalizations}

Apart from the well-defined exceptions to which we will return, the relative order of the adverbials (within or across the zones) in Isbukun is rigidly fixed, as can be seen by considering the relative order of any two pairs of them.

To start with, a fixed order can be shown to characterize higher adverbials. As illustrated in (20)-(21), speech act adverbials precede epistemic adverbials, which

21. The form paisna is the causative version of a spatial prefix maisna "from". In many Isbukun subdialects, 'from yesterday' can be translated as maisna takna with the intransitive version of a spatial prefix 'from. 
in turn precede volitional adverbials. This gives us the (partial) relative order for the higher Mood/Modal adverbial classes: speech act > epistemic > volitional.

(20) speech act $>$ epistemic
a. Tumantuk, m-aszang Tahai ma-dahpa. ${ }^{22}$
AV.tell-the-truth AV-seemingly Tahai AV-sick
'To tell the truth, Tahai seems sick.'
b. ${ }^{*}$ M-aszang tumantuk Tahai ma-dahpa.

(21) epistemic > volitional
a. M-aszang kamananu Abus ma-ludah zaku. AV-seemingly AV.intentionally Abus AV-hit 1sG.ACC
'Seemingly, Abus hit me on purpose.'
b. ^Kamananu m-aszang Abus maludah zaku.

Moreover, (22) shows that volitional adverbials must occur to the left of the repetitive adverbials. Given (22) and that volitional adverbial type occupies the lowest portion of the higher adverbial domain, by the law of transitivity we obtain the order in which the major semantic class of Modal-related adverbials precedes Aspect-related adverbials.

(22) volitional $>$ repetitive
a. Kamananu sảia mu-uhna kantundah zaku. Av.intentionally 3sG.NOM AV-again AV.kick 1sG.ACC
'He intentionally kicked me again.'
b. *Mu-uhna sa’ia kamananu kantundah zaku.

Next we consider those adverbials that occur in the lower part of the clause. A repetitive adverbial like muuhna 'again' precedes a prospective adverbial like mungaa 'almost' and cannot follow it.

(23) repetitive $>$ prospective
a. Mu-uhna sa’ia mungaa ma-pizaipuh mas lulubunun. AV-again 3sG.NOM AV.almost AV-boil aCC egg 'He almost boiled eggs again.'
b. *Mungaa sảia mu-uhna ma-pizaipuh mas lulubunun.

\footnotetext{
22. The relationship between epistemicity and evidentiality has long been known to be close and thus difficult to demarcate. Here I treat maszang as involving epistemic modality since it involves the speaker's evaluation, judgment and degree of commitment attached to the truthvalue of a piece of information but does not implicate any need to assert the source or evidence at their disposal, which is the job of evidentiality (De Haan 2001, Nuyts 2005).
} 
What's more, a prospective adverbial like mungaa 'almost' necessarily precedes a manner adverbial mabiskav 'quickly' but not vice versa, as shown in (24).

(24) prospective $>$ manner

a. (Mais balivus-an hai,) mungaa naia ma-biskav munhanu. when typhoon-LV TOP AV.almost 3PL.NOM AV-quickly AV.float 'During the typhoon, they almost floated away quickly.'

b. *(Mais balivusan hai,) ma-biskav naia mungaa munhanu.

Putting together the pairwise relative orders considered so far, we have arrived at the following characterization of Isbukun adverbial ordering: an ordered sequence of higher adverbials precedes an ordered sequence of lower adverbials, with the hierarchy of speech act $>$ epistemic $>$ volitional $>$ repetitive $>$ prospective $>$ manner. ${ }^{23}$ Note, however, that the relative ordering restrictions pointed out here hold generally with regard to adverbial verbs across different zones; that is, ordering variation within the same adverbial class is possible as long as no semantic anomaly results. As shown in (25), when two adverbials of the same class, in this case manner adverbials, co-occur in a clause, ordering variation is conceivable. Nevertheless, the ordering variation within an adverbial type does not affect our main point here that in Isbukun Bunun the semantically distinct adverbial classes are strictly ordered and each has to appear in its own separate licensing configuration, as outlined in Cinque's theory.

(25) a. Mu-daukdauk sa’ia ma-nanulu ka-libus.

AV-slowly 3sG.NOM AV-carefully AV.cut-tree

'He cut the tress carefully and slowly.'

b. Ma-nanulu sa'ia mu-daukdauk ka-libus.

AV-carefully 3sG.NOM AV-slowly AV.cut-tree

'He cut the tress slowly and carefully'.

Recall that we have shown previously that certain adverbial modifiers in Isbukun do not bear typical verb properties but rather should be treated as real adverbs. As they are not verbs but Isbukun being a strictly verb-initial language, it is thus difficult to elicit sentences to make pairwise ordering comparisons in a similar way to what we did with the adverbial verbs above. Nevertheless, as already shown in Section 2, these 'genuine' adverbs are freer in their distribution and allowed

23. As is oft-seen in the adverb cartographic studies, not all orders expected by transitivity are exhaustively documented in the data presented here and it is sometimes difficult to elicit sentences with stacked adverbials in the first place. Nevertheless, what we have observed in Isbukun are generally in congruity with the widely attested orders in other languages. Crucially, for the current purpose, the rigid order presented here suffices us to show that Isbukun adverbial verbs respect the ordering restrictions imposed on them. 
to occur in various clausal-internal positions. Such order flexibility can also be shown in their relationship to certain adverbial verbs under carefully-controlled conditions as in (26). ${ }^{24}$

(26) Ma-ngaspah tu bunun hai, nii (amin) mahtu (amin) ma-biskav (amin)

AV-fat LNK person TOP NEG also AV.can also AV-quickly also

m-udadaan (amin).

AV-run also

'Fat people can't run quickly either.'

For instance, in (26) the additive adverb amin 'also' allows up to four possible slots, and it can show up on either side of the manner adverbial verb mabiskav 'quickly'. Similarly, in (27) the emphatic adverb tutupa 'surely' can occur in any of the three bracketed positions and no ordering restriction with respect to the completive adverbial is imposed on it.

(27) Inaak tu bananaz hai, niang (tutupa) ma-zingzav (tutupa) kanahtung 1sG.GEN LNK husband TOP NEG surely AV-completely surely av.finish is-kuzakuza (tutupa).

NML-work surely

'My husband surely hasn't completely got the work done.'

In other words, these non-verbal phrasal adverbs turn out to be exactly the adverbs that do not need to respect rigid ordering in Isbukun. Before we progress further, two notes of clarification are in order concerning the patterns observed in (26)-(27).

First of all, the different adverb positions do not seem to contribute to significant scope or meaning differences since there is no perceptible change in interpretation among the distinct placement. In all of the positions, amin in (26) yields the additive reading in that it functions to add "fat people" to the group of "people who cannot run very fast" and, crucially, the position alteration induces no noticeable construal differences. The same goes for (27): tutupa 'surely', in the three possible slots, carries the affirmative force to the denoted proposition equally.

The second note of importance concerns the relationship between order flexibility and adverb semantics. As we have shown, those adverbs which do not bear typical verb properties are adverbs that entertain relatively free distribution.

24. In order to make the ordering alternations possible, we have to construct sentences with their sentence-initial position being occupied by some other element first, such as negation markers. As such, sentences of this sort are rather difficult to elicit since they are highly semantically-restricted. Note that if we change sentences (26) and (27) to be affirmative and leave out the negation, amin and tutupa then cannot occur in the clause-initial position. 
We suggest, therefore, it is the adverbials which are not realized as heads but as phrases that do not need to observe ordering restrictions; that is, non-head adverbs can freely participate in the sentence. However, one might raise objections to such a generalization and instead propose a semantics-oriented alternative such that the aforementioned patterns arise as a result of the semantics these adverbs bear. As one may notice, amin and tutupa both are focus-sensitive adverbs; as such, it seems conceivable to tie their greater order flexibility to their semantic properties. Nevertheless, this alternative should be rejected for the reasons laid out in the following.

In addition to the phrasal adverb tutupa, the concept of certainty can also be expressed by another adverb nanu 'surely' in Isbukun. Though the two are semantically identical, they bear notable syntactic disparities. Specifically, different from tutupa, nanu displays unequivocal verbal properties: it has to occur sentence-initially (28a) and can take voice morphology as well as attract pronominal clitics (28b). This type of behavior is in stark contrast to that of tutupa in (9b), (14a) and (17e), repeated here in (29a) to (29c).

(28) a. Nanu sa'ia tu mazima isaicia cina.

AV.surely 3sG.NOM LNK AV.love 3sG.GEN mother

'He surely loves his mother.'

b. Nanu-un-ku Bukun ma-ludah.

surely-PV-1sG.OBL Bukun Av-hit

'Bukun will surely be hit by me.'

(29) a. Min-sial tutupa isaicia lutbu.

Av.become-good surely 3sG.GEN body

'His body will surely get better.'

b. Hanup tu bunun mais sadu cici hai, pataz-un tutupa.

AV.hunt LNK person when AV.see prey TOP kill-PV surely

'When a hunter sees his prey, the prey will surely be killed.'

c. Ma-daidaz-ta uvaaz tutupa.

AV-love-1PL.NOM child surely

'We surely love children.'

What's more intriguing, nanu is considerably restricted in terms of its clausalinternal distribution, relative to other adverbial types. Consider the following for example:

(30) a. Nanu sa’ia ma-zingzav-in kanahtung is-kuzakuza. AV.surely 3sG.NOM AV-completely-PRF AV.finish NML-work 'He surely has completely got the work done.' 
b. *Ma-zingzav-in sa’ia nanu kanahtung is-kuzakuza. AV-completely-PRF 3sG.NOM AV.surely AV.finish NML-work 'He surely has completely got the work done.'

As illustrated in (30), when stacked with the completive adverbial in a given clause, nanu must precede it; reversal of this order (i.e., placing nanu to the right of mazingzav 'completely') will inevitably result in ungrammaticality. In other words, nanu needs to comply with a fixed adverbial hierarchy as also observed with other adverbial verbs in Isbukun. Crucially, however, recall that we have already shown the semantically similar tutupa can be preceded by mazingzav 'completely', as repeated below. Therefore, it is clear that semantic reasons cannot be the factor which rules out (3ob).

(31) Inaak tu bananaz hai, niang ma-zingzav tutupa kanahtung 1sG.GEN LNK husband TOP NEG AV-completely surely AV.finish is-kuzakuza.

NML-work

'My husband surely hasn't completely got the work done.'

Accordingly, this range of facts warrants the current generalization that in Isbukun the syntactic status of a given adverbial element strongly interrelates with ordering restrictions; semantic considerations alone would fall short of capturing such a correlation.

\subsection{Towards a theoretical account}

Current syntactic theories concerning the status of adverbs can be divided into two main groups in terms of how adverbs are licensed in the phrase structure and how the ordering variations reflect such licensing structural configurations.

First is the adjunction theory (Ernst 2002, 2007, Kaufman 2004, among others). Based on the observation that adverbs are apparently optional and enjoy certain flexibility in placement, advocates of this view hold that, with occasional exceptions, adverbs adjoin to maximal projections freely so far as syntax is concerned. Therefore, as long as an adverb and its adjunction site are semantically compatible, the adverb can then be legitimately licensed. This amounts to saying that there is no need to fix the structural positions of adverbs and the apparent restrictions on their linear ordering really boil down to semantics.

The second approach is the functional specifier theory. Largely motivated by the observation that, crosslinguistically, different classes of adverbs and their relative order predominantly correspond to the classes and relative order of functional morphemes, proponents of this theory (see Alexiadou 1997, Cinque 1999, 
2004 among others) argue that adverbs are located in unique specifier positions of distinct functional projections, whose order is fixed in Universal Grammar. In this view, the apparent free, mutable positions of adverbs are ascribed to movement of their surrounding (non-adverb) elements rather than that of the adverbs themselves (see a detailed discussion in Cinque 1999:16-28). ${ }^{25}$

Additionally, based on relevant phenomena in Formosan languages, Holmer (2012) proposes another alternative which essentially differs from the adjunction theory and the functional specifier theory. He argues that adverbial elements of Formosan languages occupy head positions, for which the adjunction model falls short of accounting. On the other hand, though he assumes that a universal structure consisting of discrete ordered adverbial categories does exist and the adjunction mechanism should be abolished, he considers the ordering to be semantically determined along the line suggested by Ernst.

So far we have shown that adverbial elements in Isbukun can be divided into two morpho-syntactically distinct groups: adverbial verbs and adverbs. Adverbial verbs occupy typical verbal head positions and enter a rigidly ordered sequence, whereas adverbs are non-head phrasal categories freely distributed within their semantic scope. Next let us consider further the theoretical implications of the Isbukun data on the theories of adverbials. ${ }^{26}$

As already argued in Holmer (2010), the verbal nature of adverbial verbs in many Formosan languages follows trivially if the adverbial element is assumed to be merged in the head position, from where it is able to take the relevant verbal morphology and allow cliticization. A similar view applies to Isbukun. In particular, we contend that adverbial verbs are not adjoined to the clause; rather, they reside in the head positions of the corresponding functional adverbial projections. In other words, the facts in Isbukun partially conform to Cinque's proposal of a rigidly-ordered adverbial hierarchy but differ in the actual implementation of placing the adverbials in head- or specifier- positions. ${ }^{27}$

25. In cases where two spaces seem to exist for adverbials, Cinque gives evidence to show that they are actually adverbials "systematically ambiguous between two interpretations, each associated with a different position" (Cinque 1999:26).

26. According to $\mathrm{Su}$ (2008), adverbial modifiers in Takituduh Bunun are realized as verbs, including temporal adverbials. Moreover, Su argues that epistemic adverbials occur before all the other adverbials while manner adverbials occur in the structurally lowest position; between the two ends, the remaining adverbials are interspersed with no specific ordering restrictions. Thus Takituduh and Isbukun appear to differ considerably in these respects, which deserves further examination.

27. The deeper question to address is why some languages choose to realize adverbs as heads rather than as phrases and the solution is beyond the scope of this paper. For some relevant discussion, readers can refer to Holmer (2012) and references therein. 
On the other hand, the Isbukun data also show that adjunction should be kept as a separate mechanism à la Ernst (2007). Specifically, despite the limited cases, Isbukun has adverbs such as amin 'also' and tutupa 'surely' which retain archetypal adverb properties (i.e., phrasal, free distribution). Their behavior would be difficult, if not impossible, to be accommodated under Cinque's universal ordering principles given that they do not enter a fixed ordering sequence and the order change produces no perceptible semantic outcome either.

In other words, Isbukun Bunun adverbial expressions demonstrate a mixed picture in adverbial licensing: its adverbial verbs correspond to adverbs with relatively fixed placement in languages like English or Italian, whereas true adverbs in Isbukun Bunun display functions which in English also entertain substantial placement variation. As such, we can say that, on one hand, the facts regarding adverbial verbs lend support to the program outlined in Cinque that relies on syntactic devices and takes the universal hierarchy of functional projections as mandated by Universal Grammar, while, on the other hand, the properties of genuine adverbs pinpoint the need to also allow a system that accommodates scopally flexible adjunction since a given adverb may occur in multiple positions with no meaning difference, something explicitly barred from Cinque's perspective.

Another important facet worth noting concerns the nature of the rigidly fixed adverbial hierarchy. As described earlier, Kaufman (2004), Ernst (2002, 2007), and Holmer (2010) have argued that the fixed series of adverbial levels should be determined semantically; if such functional elements are viewed as logical operators on the clausal structure, the observed ordering can then be reduced to direct reflections of the intrinsic logical operator ordering. However, what has been observed in Isbukun, at least in some data, reveals that the hierarchy should be considered an independent grammatical construct of the computational system, not easily reducible to the semantic component. In particular, though, admittedly, most cases of relative order among adverbials are seemingly explicable in terms of their semantic relations, not all can be treated in the same way. For instance, recall in the last section we showed that the adverbial of certainty nanu 'surely' cannot be lower than the Asp-related completive adverbial mazingzav 'completely'. Crucially, however, there shouldn't be any definite ban on having a certainty-denoting adverbial embed under a completive adverbial, as such ordering is perfectly acceptable with tutupa 'surely' being lower than mazingzav 'completely' as seen in (31). As a result, the rigid ordering of the two classes of element cannot seem to be totally ascribable to the logical (in-)congruity of their relative scope. In other words, though the ordering of adverbial verbs does have semantic underpinning to some degree, it does not dissolve into scoping or semantic composition. 


\section{Conclusion}

In this paper, I have provided a systematic description of the adverbial expressions in Isbukun Bunun. The relevant data shows that, in this language, most adverbial meanings are realized as verbs, with only a few sporadic cases of adverbial expressions realized as adverbs in the traditional sense. The adverbial verbs, just like typical verbs, have to occur sentence-initially, take verbal morphology and attract cliticization, whereas the genuine 'adverbs' are invariable in form and exhibit relatively free distribution. Moreover, I have shown that the relative order of the adverbial verbs is rigidly fixed across the semantic zones and the ordering algorithm cannot be entirely reduced to the semantic component, which supports Cinque's (1999) proposed functional projection hierarchy. On the other hand, the behavior of phrasal adverbs in Isbukun nevertheless points to the non-eliminability of adjunction mechanism along the lines suggested by Ernst (2002, 2010). Recent controversies about the nature of adverb placement center around the question as to whether or not it is governed by a universal hierarchy of functional projections. This study, therefore, presents evidence bearing on the debate concerning the syntax of adverbials and shows that a hybrid treatment is needed, in which phrasal adverbs are adjoined to clauses while adverbial verbs in Isbukun Bunun, showing substantial head-like properties, are located in the strictlyordered functional projections in the backbone of the clause.

\section{Acknowledgements}

My sincere gratitude goes to Taupas Tansikian for all the assistance and unfailing support he has provided in my study of Isbukun Bunun over the years. I am also grateful for helpful comments from the anonymous reviewers and editors. These helped me greatly in clarifying various points and improving the paper. All remaining errors are my own responsibility. 


\section{List of abbreviations}

$\begin{array}{ll}1 & \text { first person } \\ 2 & \text { second person } \\ 3 & \text { third person } \\ \text { ACC } & \text { accusative } \\ \text { AV } & \text { actor voice } \\ \text { BV } & \text { beneficiary voice } \\ \text { DEM } & \text { demonstrative } \\ \text { FUT } & \text { future } \\ \text { GEN } & \text { genitive } \\ \text { IMP } & \text { imperative } \\ \text { LNK } & \text { linker } \\ \text { LV } & \text { locational voice } \\ \text { NEG } & \text { negation }\end{array}$

$\begin{array}{ll}\text { NOM } & \text { nominative } \\ \text { NML } & \text { nominalizer } \\ \text { OBL } & \text { oblique } \\ \text { OPT } & \text { optative } \\ \text { P } & \text { preposition } \\ \text { PART } & \text { particle } \\ \text { PFV } & \text { perfective } \\ \text { PL } & \text { plural } \\ \text { PRF } & \text { perfect } \\ \text { PV } & \text { patient voice } \\ \text { Q } & \text { question marker } \\ \text { SG } & \text { singular } \\ \text { TOP } & \text { topic }\end{array}$

\section{References}

Alexiadou, Artemis. 1997. Adverb Placement: A Case Study in Antisymmetric Syntax. Amsterdam: John Benjamins. https://doi.org/10.1075/la.18

Chang, Henry Y. 2006. The guest playing host: Adverbial modifiers as matrix verbs in Kavalan. Clause Structure and Adjuncts in Austronesian Languages, ed. by Hans Martin Gärtner, Paul Law and Joachim Sabel, 43-82. Berlin: Mouton de Gruyter. https://doi.org/10.1515/9783110922974.43

Chang, Henry Y. 2009. Adverbial verbs and adverbial compounds in Tsou: A syntactic analysis. Oceanic Linguistics 48.2:439-476. https://doi.org/10.1353/ol.0.0042

Cinque, Guglielmo. 1999. Adverbs and Functional Heads: A Cross-linguistic Perspective. New York \& Oxford: Oxford University Press.

Cinque, Guglielmo. 2004. Issues in adverbial syntax. Lingua 114.6:683-710. https://doi.org/10.1016/So024-3841(03)00048-2

De Haan, Ferdinand. 2001. The place of inference within the evidential system. International Journal of American Linguistics 67.2:193-219. https://doi.org/10.1086/466455

Ernst, Thomas. 2002. The Syntax of Adjuncts. Cambridge, UK: Cambridge University Press.

Ernst, Thomas. 2007. On the role of semantics in a theory of adverb syntax. Lingua 117.6:1008-1033. https://doi.org/10.1016/j.lingua.2005.03.015

Ernst, Thomas. 2010. Adverbs and light verbs. Proceedings of the 22rd North American Conference on Chinese Linguistics (NACCL-22) and the 18th International Conference on Chinese Linguistics (IACL-18), ed. by Lauren Eby Clemens and Chi-Ming Louis Liu, 178-195. Cambridge, MA: Harvard University.

Grimshaw, Jane. 1991. Extended projection. Manuscript, Brandeis University, Waltham, MA. He, Ru-fen, Si-qi Zeng, Wen-shu Li, and Qing-chun Lin. 1986. Gaoshanzu Yuyan Jianzhi: Bunenyu [A Handbook of the Mountain Indigenous Peoples: Bunun]. Beijing: Minzu. 
Holmer, Arthur. 2006. Seediq - Adverbial heads in a Formosan language. Clause Structure and Adjuncts in Austronesian Languages, ed. by Hans-Martin Gärtner, Paul Law and Joachim Sabel, 83-123. Berlin: Mouton de Gruyter. https://doi.org/10.1515/9783110922974.83 Holmer, Arthur. 2010. Seediq adverbial verbs - A review of the evidence. Austronesian and Theoretical Linguistics, ed. by Raphael Mercado, Eric Potsdam and Lisa deMena Travis, 163-182. Amsterdam: John Benjamins. https://doi.org/10.1075/la.167.11hol

Holmer, Arthur. 2012. Evidence from Formosan for a unified theory of adverb ordering. Lingua 122.8: 902-921. https://doi.org/10.1016/j.lingua.2012.03.003

Hsiao, Yi-ling. 2004. Adverbials in Squliq Atayal. MA thesis, National Tsing Hua University, Hsinchu.

Huang, Hui-chuan J. 2008. Competition between syllabic and metrical constraints in two Bunun dialects. Linguistics 46.1:1-32. https://doi.org/10.1515/LING.2008.001

Huang, Lillian M. 1997. Kaohsiungxian de bunongyu [The Bunun language in Kaohsiung County]. Kaohsiungxian de Nandao Yuyan [Austronesian Languages Spoken in Kaohsiung County], ed. by Paul Jen-kuei Li, 351-409. Kaohsiung: The Government of Kaohsiung County.

Huang, Lillian M., Elizabeth Zeitoun, Marie M. Yeh, Anna H. Chang, and Joy J. Wu. 1999. A typological overview of pronominal systems of some Formosan languages. Selected Papers from the 5th International Conference on Chinese Linguistics, ed. by Samuel Wang, Feng-fu Tsao and Chin-fa Lien, 165-198. Taipei: Crane.

Jeng, Hengsyung. 1977. Topic and Focus in Bunun. Taipei: Institute of History and Philology, Academia Sinica.

Jeng, Hengsyung. 1999. Bunun tense and aspect. Selected Papers from the Eighth International Conference on Austronesian Linguistics, ed. by Elizabeth Zeitoun and Paul Jen-kuei Li, 455-487. Taipei: Institute of Linguistics, Academia Sinica.

Kaufman, Daniel. 2004. Adverbs at the interface. Paper presented at the 11th Annual Meeting of the Austronesian Formal Linguistics Association (AFLA-11), ZAS, Berlin.

Kaufman, Daniel. 2006. Rigidity versus relativity in adverbial syntax: Evidence from Tagalog. Clause Structure and Adjuncts in Austronesian Languages, ed. by Hans-Martin Gärtner, Paul Law and Joachim Sabel, 151-194. Berlin: Mouton de Gruyter. https://doi.org/10.1515/9783110922974.151

Li, Chao-Lin. 2007. Adverbial verbs and argument attraction in Puyuma. Nanzan Linguistics, Special Issue 3.1:165-201.

Li, Lilian L. 2010. Clitics in Nantou Isbukun Bunun (Austronesian). MA thesis, National Chi Nan University, Nantou.

Li, Lilian L. 2017. Verb-adjacent clitic climbing and restructuring in Isbukun Bunun. Oceanic Linguistics 56.1:1-21. https://doi.org/10.1353/ol.2017.0000

Li, Lilian L. 2018. A Grammar of Isbukun Bunun. Doctoral dissertation, National Tsing Hua University, Hsinchu.

Li, Paul J.-K. 1988. A comparative study of Bunun dialects. Bulletin of the Institute of History and Philology 59:479-508.

Li, Paul J.-K. 1997. The southern dialect of Bunun spoken in Xinyi Township, Nantou County. Kaohsiungxian de Nandao Yuyan [Austronesian Languages Spoken in Kaohsiung County], ed. by Paul Jen-kuei Li, 300-350. Kaohsiung: The Government of Kaohsiung County.

Li, Paul J.-K. 2016. Verbs or adverbs in Thao? Concentric: Studies in Linguistics 42.1:31-44. 
Lin, Hsiu-hsu. 1996. Isbukun Phonology: A Study of its Segments, Syllable Structure and Phonological Processes. MA thesis, National Tsing Hua University, Hsinchu.

Nojima, Motoyasu. 1996. Lexical prefixes of Bunun verbs. GENGO KENKYU 110:1-27.

Nuyts, Jan. 2005. Modality: Overview and linguistic issues. The Expression of Modality, ed. by William Frawley, 1-26. Berlin: Mouton de Gruyter.

Ross, Malcolm, and Stacy Fang-Ching Teng. 2003. The notion of verb in Puyuma: A construction grammar approach. Paper presented at the 2nd Workshop on Formosan Languages, Academia Sinica, Taipei.

Shi, Chaokai. 2009. The Linker $t u$ in Isbukun Bunun. MA thesis, National Kaohsiung Normal University, Kaohsiung.

Starosta, Stanley. 1988. A grammatical typology of Formosan languages. Bulletin of the Institute of History and Philology 59: 541-576.

Stump, Gregory T. 2001. Inflectional Morphology: A Theory of Paradigm Structure. Cambridge, UK: Cambridge University Press. https://doi.org/10.1017/CBO9780511486333

$\mathrm{Su}$, Yi-Fan. 2008. Adverbials in Takituduh Bunun. MA thesis, National Tsing Hua University, Hsinchu.

Wu, Chunming. 2004. A Study of Lexical Categories in Paiwan. MA thesis, National Chung Cheng University, Chiayi.

Wu, Chunming. 2006. Adverbials in Paiwan. Paper presented at the 1oth International Conference on Austronesian Linguistics, Palawan, Philippines.

Yeh, Marie Meili. 2003. Adjectives as verbs in Saisiyat. Paper presented at the 2nd Workshop on Formosan Languages, Academia Sinica, Taipei.

Zeitoun, Elizabeth. 200o. Bunongyu Cankao Yufa [A Reference Grammar of Bunun]. Taipei: Yuanliou.

Zeitoun, Elizabeth. 2007. A Grammar of Mantauran Rukai. Taipei: Academia Sinica.

\section{Address for correspondence}

Hsiao-hung Iris $\mathrm{Wu}$

Department of English

National Taiwan Normal University

Taipei, TAIWAN

Hsiao-hung Iris Wu: iriswu@ntnu.edu.tw

\section{Publication history}

Date received: 3 May 2018

Date revised: 3 July 2018

Date accepted: 20 December 2018

Published online: 31 May 2019 